\title{
Organizational Learning and Physical Space- How Office Configurations Inform Organizational Behaviors
}

\section{Kerstin Sailer}

\begin{abstract}
Although discussion and perspectives in organization studies, management, industrial sociology, and geography have expanded the overall understanding of the spatial context and location of learning organizations, little is known about the microsettings and architectural configuration of spaces that promote collective action. Exploring this aspect of the relation between space and organizations, the author examines knowledge-intensive work processes in a German research institution to identify how architectural space (a building's spatial configuration) relates to collective action and organizational learning. Qualitative and quantitative methodologies, including a space syntax analysis of spatial configuration, are used to document spatial configuration, space usage, and patterns of interaction and knowledge-sharing in relation to other knowledge-intensive work environments. A narrative of life in the organization depicts physical space as a factor of organizational learning. The author considers the effects of spatiality and transpatiality on organizational behavior to challenge the common association between geodeterminism and the study of physical space.
\end{abstract}

\section{Organizational Learning and the Physical Environment}

Organizational learning, the way in which an organization as a whole adapts, changes, creates, and shares knowledge and reformulates its strategies in a structured way, has been a major concern of scholars in organization studies since the early 1960s, when Burns and Stalker (1961) and Cyert and March (1963) first brought up the topic. During the 1990s in particular, at the same time as knowledge management became a popular issue in organization studies, an increasingly broad discourse on organizational learning emerged. Proposing a rich variety of definitions and concepts of organizational learning, scholars advanced the idea that learning within organizations or by organizations had multiple drivers. They included, among many others, individual cognition (Hedberg, 1981; March \& Olsen, 1976; Starbuck, 1992); group learning (Nonaka \& Takeuchi, 1995); information acquisition and processing (Argyris \& Schön, 1996; Huber, 1991); knowledge creation and sharing (Argote, 1999; Duncan \& Weiss, 1979; Levinthal, 1991; March, 1991; March, Sproull, \& Tamuz, 1991); dialogue and communication (Chawla \& Renesch, 1995; Isaacs, 1999); overcoming inhibitors or learning from failures (Ackermann, 2005; Argyris \& Schön, 1996; Dilworth, 1995; Sitkin, 1996); organizational cultures (Cook \& Yanow, 1996; Klein, 1999); interpretations, experiences, and sense-making (Levitt \& March, 1996; March \& Olsen, 1976; March et al., 1991; Weick, 1995; Weick \& Roberts, 1993); and environmental cues (Argote, 1999; Levinthal \& March, 1993; Probst \& Büchel, 1998; von Hippel, 1988). 
The literature on organizational learning soon came to be called voluminous and multifaceted and was criticized for its lack of a cumulative and synthesizing perspective (Huber, 1991). Acknowledging the difficulties in achieving an overarching theory of organizational learning, authors of more recent contributions have either valued the heterogeneity of approaches as a reflection of the complexity of the concept of organizational learning and its emerging pluralistic expressions (Prange, 1999) or have tried to systematize the underlying mechanisms of organizational learning (Lipshitz, Popper, \& Friedman, 2002). Still, organization learning remains a vague and predominantly theoretical concept. One rarely finds approaches for quantitatively measuring or qualitatively investigating and thus empirically validating organizational learning concepts.

A search for such approaches reveals that the mainstream discourse on the subject has widely ignored the physical reality of organizations as they strive to become learning organizations. The gap seems odd, given that space has been deemed crucial to "the social organization of everyday life" (Hillier, 1996, p. 4), a "vector of social interactions" (Fischer, 1997, p. 3), and even the "most powerful tool for inducing culture change, speeding up innovation projects, and enhancing the learning process in far-flung organizations" (Peters, 1992, p. 413). Exceptions exist, of course. Some researchers have enriched the spatial understanding of organizational learning from the perspective of economic geography, for example. Contributions since the late 1990s have recognized local clusters and spatial as well as relational proximity as important conditions for organizational learning (Amin \& Cohendet, 2004; Amin \& Roberts, 2008; Faulconbridge, 2006; Gertler,1997, 2003; Malmberg \& Maskell, 2002; Maskell \& Malmberg, 1999). A further significant clue to the role of physical space is found in the seminal contribution by Argyris and Schön (1996), who defined an organizational learning system as being composed of structures that channel organizational enquiry and shape the behavioral world of organizations. Among those structures is the spatial environment" insofar as it influences patterns of communication" (Argyris \& Schön, p. 28). It is on such insights that this chapter builds. By contrast, other attempts to explore workplace environments as stimuli of or obstacles to organizational learning(Granath, Lindahl, \& Adler, 1995; Lewis \& Moultrie, 2005) have remained vague and have not been pursued further.

It may seem surprising at first that an organization's microlevel physical embeddedness and its relevance for organizational learning have not been researched as vigorously as other aspects of the organizational environment, context, and constitution. This paucity, however, is quite consistent with the rather sparse general discourse on physical settings and organizational behavior, which has been criticized for not providing more than "scattered empirical evidence" (Gieryn, 2002, p. 46) on the relation between architectural layout and social interaction.

Yet physical space can be regarded as an affordance for organizational behavior. In this chapter physical space is seen mostly as a form of spatial configuration (i.e., the layout of floor plans). I make this delimitation for one main reason: Environmental and climatic factors (e.g., temperature, light, climate, comfort) matter most at the level of the individual. The same goes for colors, materials, forms, aesthetics, perception, and workplace satisfaction. John's preference is not Sally's, and what motivates Mary comes across only as a hindrance to Tom.

Because the main interest of this chapter is in collective action and organizational responses, physical space as understood in the following pages is confined to design choices that govern supraindividual behaviors. The delimitation derives from Hillier's (1996) investigation of space and society, in which he states that "the relation between space and social existence does not lie at the level of the individual space, or individual activity. It lies in the relations between configurations of people and configurations of space" (p. 31). This perspective can yield important insights into the nature of the relationship between organizations and their spatial constitution.

\section{Physical Space-An Affordance for Organizational Behavior}

Physical space first caught attention as a potential influence on behaviors in workplace environments in studies conducted in the Hawthorne Works in the U.S. city of Cicero, Illinois, between 1927 and 1932. In the "Hawthorne studies," as they subsequently came to be known, factors influencing the work motivation of factory workers were tested, such as changes in lighting. The study dramatically 
lacked scientific rigor and was later harshly criticized for its shortcomings and unsupported conclusions (Carey, 1967). All the same, it posited with confidence the idea that spatial variables were meaningless in explaining behaviors. This aspect of the studies was widely referred to in the years thereafter and contributed to the rise of the human relations approach, which focuses on social determinants of work rather than on physical features (Sutton \& Rafaeli, 1987).

The discourse on space and organizations revived during the 1970s and 1980s, when important empirical contributions were made (Allen \& Fustfeld, 1975; Tomlin \& Allen, 1977). But scholars also collated an array of studies and other sources from organization studies and environmental psychology (Becker, 1981; Pfeffer, 1982; Steele, 1973; Sundstrom, 1986) to underline the way(s) in which space figures in shaping organizational outcomes. Factors such as proximity, density, visibility, office layout, and furniture arrangement were seen as offering crucial affordances for the way organizations behaved. After nearly a decade of lean years, space regained popularity as a topic when the "spatial turn" came in the humanities and social sciences (Massey, 1999, pp. 9-23; Soja, 1996). The result has been an expanding body of literature on issues as diverse as collaboration (Heerwagen, Kampschroer, Powell, \& Loftness, 2004; Wineman, Kabo, \& Davis, 2009), interaction and knowledge flow (Becker \& Sims, 2001; Fayard \& Weeks, 2007; Peponis et al., 2007; Sailer \& Penn, 2007), innovation (Penn, Desyllas, \& Vaughan, 1999; Toker \& Gray, 2008), creativity (Förster, Friedman, Butterbach, \& Sassenberg, 2005; Kristensen, 2004; Meusburger, 2009; Werth \& Förster, 2002), and performance (Kampschroer \& Heerwagen, 2005; Kampschroer, Heerwagen, \& Powell, 2007; Kelter, 2006, 2007; Kelter \& Kern, 2006; Muschiol, 2006)—all of which consider the relation to spatial context and configuration.

Despite all these efforts, very little is understood about the way physical space interrelates with organizational behavior, as the following quotation from a British policy report on office spaces exemplifies:

\begin{abstract}
The ways in which office accommodation can create value for a business ... are [still] inadequately understood....

... The collective failure to understand the relationship between the working environment and business purpose puts us in the position of early 19th century physicians, with their limited and erroneous notions about the transmission of disease before the science of epidemiology had been firmly established. (Commission for Architecture and the Built Environment [CABE], 2005, pp. 1-2)
\end{abstract}

Three reasons account for this persistent lack of understanding. First, most studies on the subject have dealt with outcomes for individuals rather than for groups or the organization as a whole. Therefore, complex issues such as performance, value creation, or innovation are hardly ever conclusively studied in their relation to physical space. Second, research in the field has taken place mostly in segregated research communities ${ }^{1}$ with little overlap and collaboration. Third, studies lacked scientific rigor, so they produced contradictory findings. On open-plan environments, for example, some studies reported an increase in communication among staff members (Allen \& Gerstberger, 1973; Brookes \& Kaplan, 1972; Hundert \& Greenfield, 1969; Ives \& Ferdinands, 1974), some found that communication decreased (Clearwater, 1980; Hanson, 1978; Oldham \& Brass, 1979), and again others showed either ambiguous results or no differences from other types of office accommodation (Boje, 1971; Boyce, 1974; Sundstrom, Herbert, \& Brown, 1982). Such equivocality may partially be an effect of an incoherent and oversimplified operationalization of variables (for a more detailed criticism see Sailer, Budgen, Lonsdale, Turner, \& Penn, 2008), but it also seems that the nature of the

\footnotetext{
1 This lack of interdisciplinary communication has been criticized by Price (2007): [Concerning] business performance [there is] ... little hard evidence for the effect of physical space in office settings; ... Such evidence as could be located, especially in managerial journals, was largely anecdotal. Property economists were adept at considering buildings from an investment perspective and building management research covered the technical issues, but the evidence from a business, or even just an individual occupier's, perspective was missing. The literature has discourses on organizations and workspaces whose proponents largely ignore each other. (p. 104).
} 
entangled relationship between space and organization was long misconstrued. ${ }^{2}$ The growing complexity and range of definitions of organizational constructs only seems to have increasingly obscured the relationship between space and organizations. In essence, this indistinctness has an important consequence for the further study of the relationship between architectural space and organizational learning. The rich diversity of definitions and concepts of organizational learning may hamper attempts to improve the understanding of the bearing that physical space has on the learning processes of an organization. In order to fully embrace the entangled relationship between physical space and organizational learning without narrowing the inquiry to one kind of learning or a specific definition of organizational learning, researchers need an exploratory approach based on a combination of qualitative and quantitative methods. For 6 weeks in the summer of 2006, I therefore used ethnographic methods as well as observations techniques, interaction surveys, social network analysis (Wasserman \& Faust, 1994), and tools for the analysis of space syntax (Hillier, 1996; Hillier \& Hanson, 1984) to study a research institute in Germany that hosts theoretical physicists. Results from that research are presented in the following section.

\section{Interaction Patterns, Knowledge Flow, and Organizational Learning in a Research Institute}

The studied organization, research institute $M$, was located south of the university campus in Dresden and was part of one of Germany's major publicly funded research societies. The institute worked in the area of classical and quantum physics and attracted a variety ${ }^{3}$ of theoretical physicists. It had 181 members of staff at the time of the study and was structured into three main departments, of which two, including all subgroups and three independent research groups (8 research groups totaling 109 staff members), were studied in depth. An integral aspect of the institute's mission was that of serving the wider international community of theoretical physics by running a visitor's program at two different levels. First, the institute annually hosted around 200 incoming visitors, who stayed from 4 weeks to 1 year and who could work at the institute temporarily, facilitating collaboration between scientists. Second, the institute acted as a conference center, conducting six to ten workshops and seminars on its premises every year, with each event lasting from 1 to 4 weeks. If the organizers of such an event were external researchers, they would receive a few offices on the grounds of the institute during the workshop. Every year 1,200-1,500 visitors attended the workshops and seminars. Thus the organization was therefore extremely dynamic.

The institute occupied a three-storey comb-shaped and purpose-built complex with three adjacent guest houses constructed in 1997 by hammeskrause architekten and enlarged in 2005 to its current configuration with an additional wing (see Fig. 7.1). Most of the workspaces were single and double offices on the first and second floor of the building. Some scientists had to be accommodated in refurbished apartments of Guest House 3 for lack of space. Figures 7.2, 7.3, and 7.4 illustrate the look and feel of the research institute.

\footnotetext{
${ }^{2}$ Only fairly recent contributions (Amin \& Roberts, 2008; Fayard \& Weeks, 2007) have started suggesting more complex models of a mutual and embedded relationship between the spatial and social realm.

${ }^{3}$ The main research areas of the institute were quantum physics of condensed matter, nonlinear phenomena and dynamics, and biophysics. The physicists interviewed for this project regarded their institute as very "interdisciplinary," even though they had all studied the same subject. Nonetheless, the focus and methodologies used varied significantly.
} 


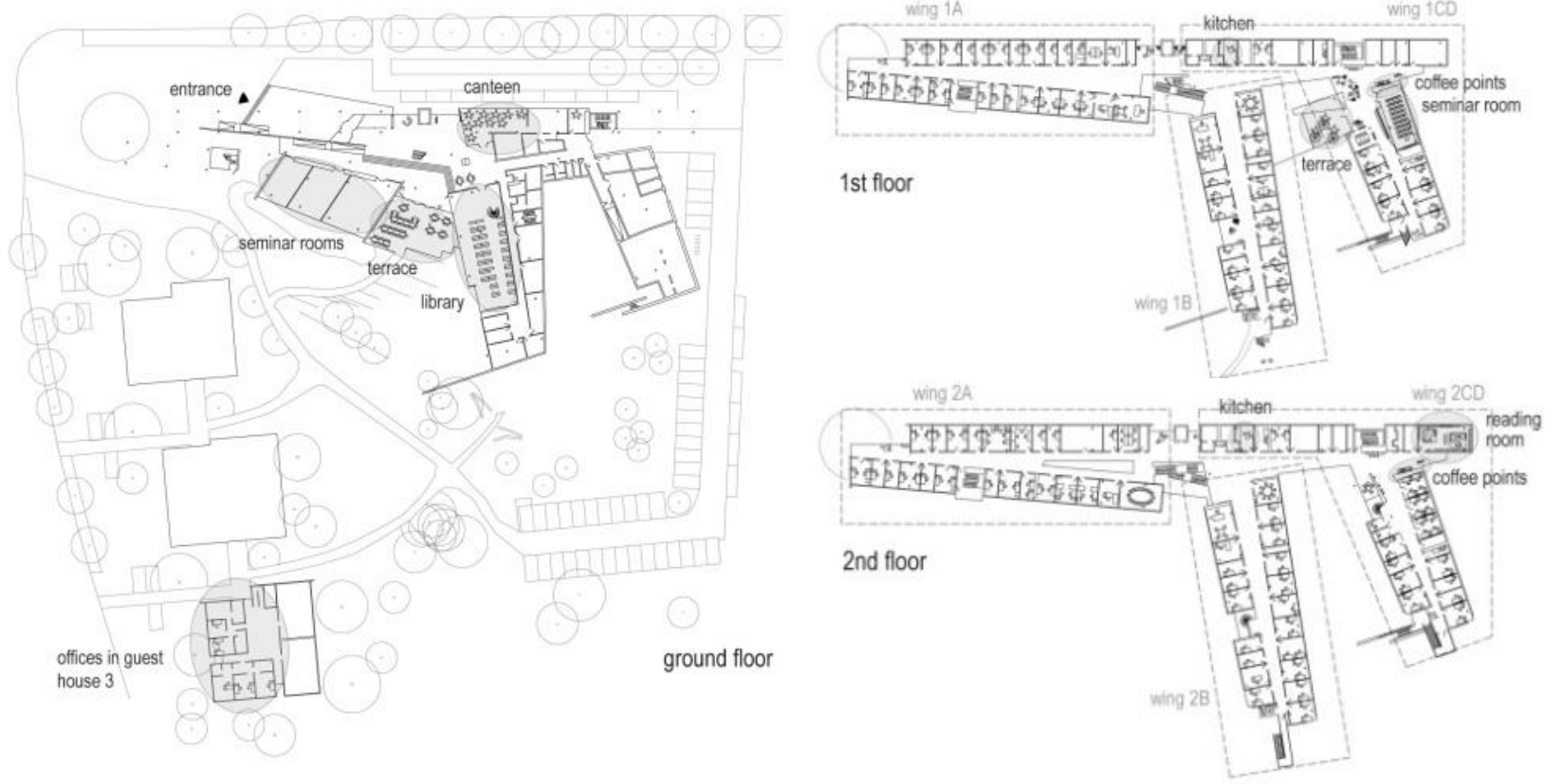

Fig. 7.1 Floor plans of the research institute, with some of the main functions and facilities highlighted (Copyright 2006, design by hammeskrause architekten; annotations by Kerstin Sailer. Adapted with permission)

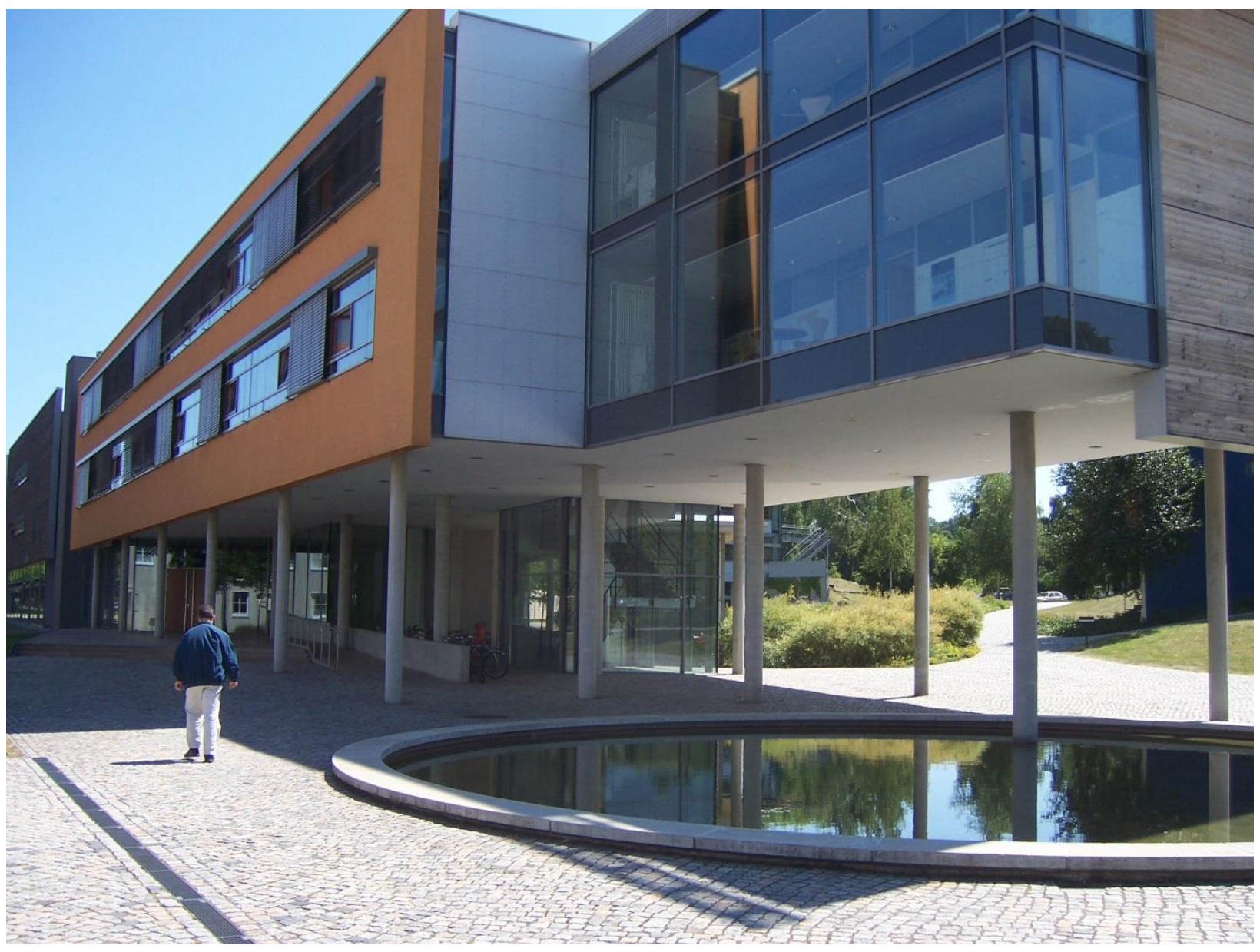

Fig. 7.2 Exterior view of the research institute (From Sailer 2010, p. 83. Copyright 2010 by K. Sailer) 


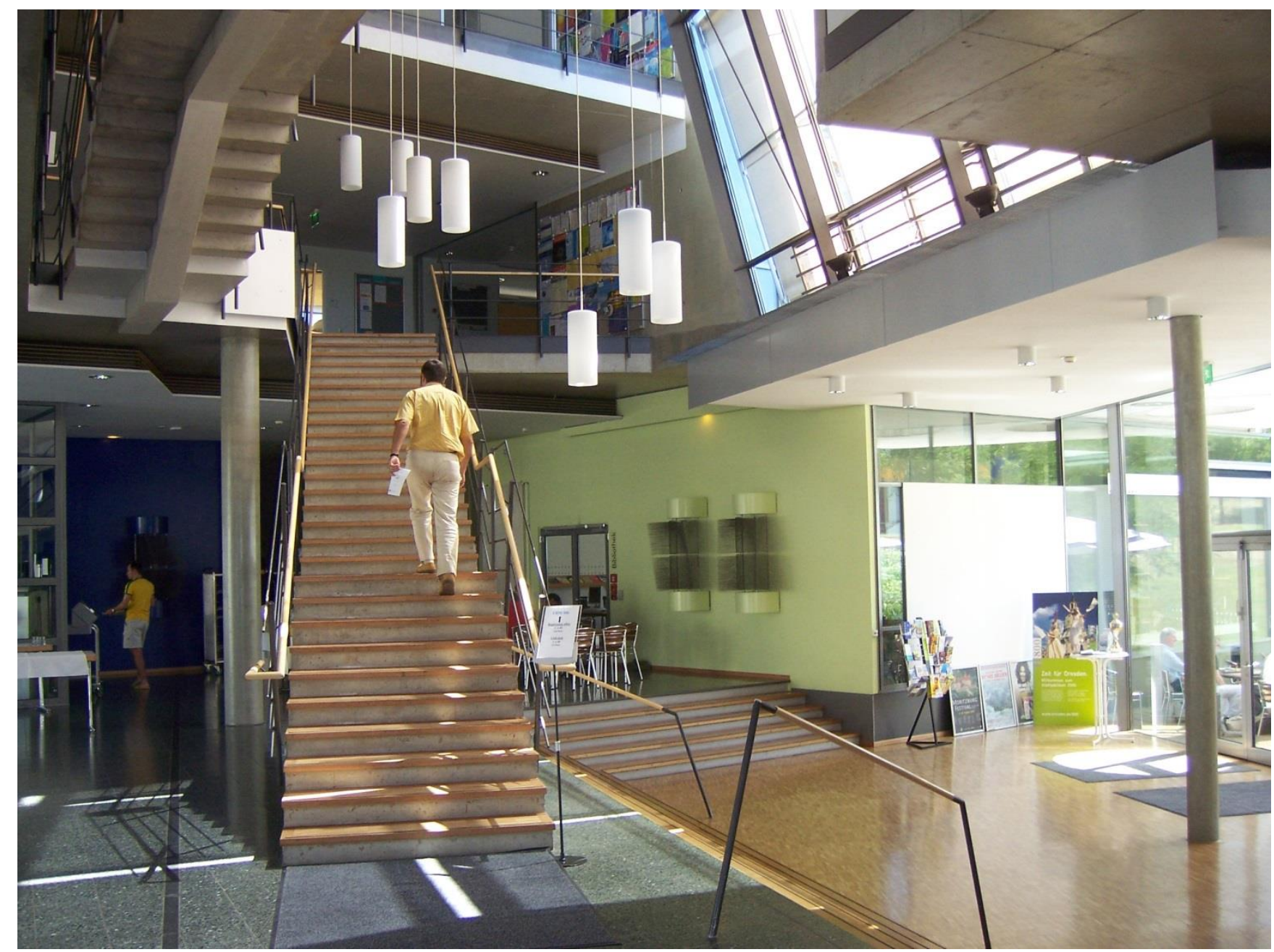

Fig. 7.3 The bright and open entrance of the research institute (From Sailer 2010, p. 83. Copyright 2010 by K. Sailer)

The next three sections explain the emergence of patterns of interaction, collaboration, and knowledge flow emerged at the research institute, the degree to which the patterns were informed by spatial configuration, and the embedding of organizational learning in physical space. First, I contend that the intensity of collaboration in knowledge-intensive workplace environments across a selection of different organizations was driven by the spatial integration of the building that an organization occupies. The case of the research institute is discussed among other cases that served as a benchmark. ${ }^{4}$ I assert that space exerts a "generic function" (Hillier, 1996, p. 284). Second, even though the frequency of interaction was affected by spatial parameters such as the distance between the workstations of individuals, I show that this distance-dependency of interactions is far less pronounced in the studied research institute than in similar cases. This finding gives rise to an argument on the specific interplay between forms of "spatial and transpatial solidarity" (Hillier \& Hanson, 1984, p. 20) in workplaces. In particular, I outline how both forms of solidarity were enacted in the research institute. Third, a software development project undertaken by one of the research groups in the institute is examined in order to understand an organizational learning situation. It

\footnotetext{
${ }^{4}$ A benchmark of 11 knowledge-intensive organizations from the public sector (universities and research institutions) and the private sector (media businesses) whose members had all studied with a similar methodology and setup was available to me through involvement in a collaborative research project entitled "Effective Workplaces" conducted by University College London and Spacelab Architects, London. (Some of the results are published in Sailer, Budgen, Lonsdale, Turner, \& Penn, 2009.) The benchmark consisted of syntactical features of space (visibility, metric integration of the building) and survey data on interaction and collaboration patterns of the organizations (interaction frequency and the intensity of collaboration).
} 
becomes evident how spatial configuration aided various steps involved in the collective learning process. This example emphasizes the entangled nature of the relationship between space and an organization.

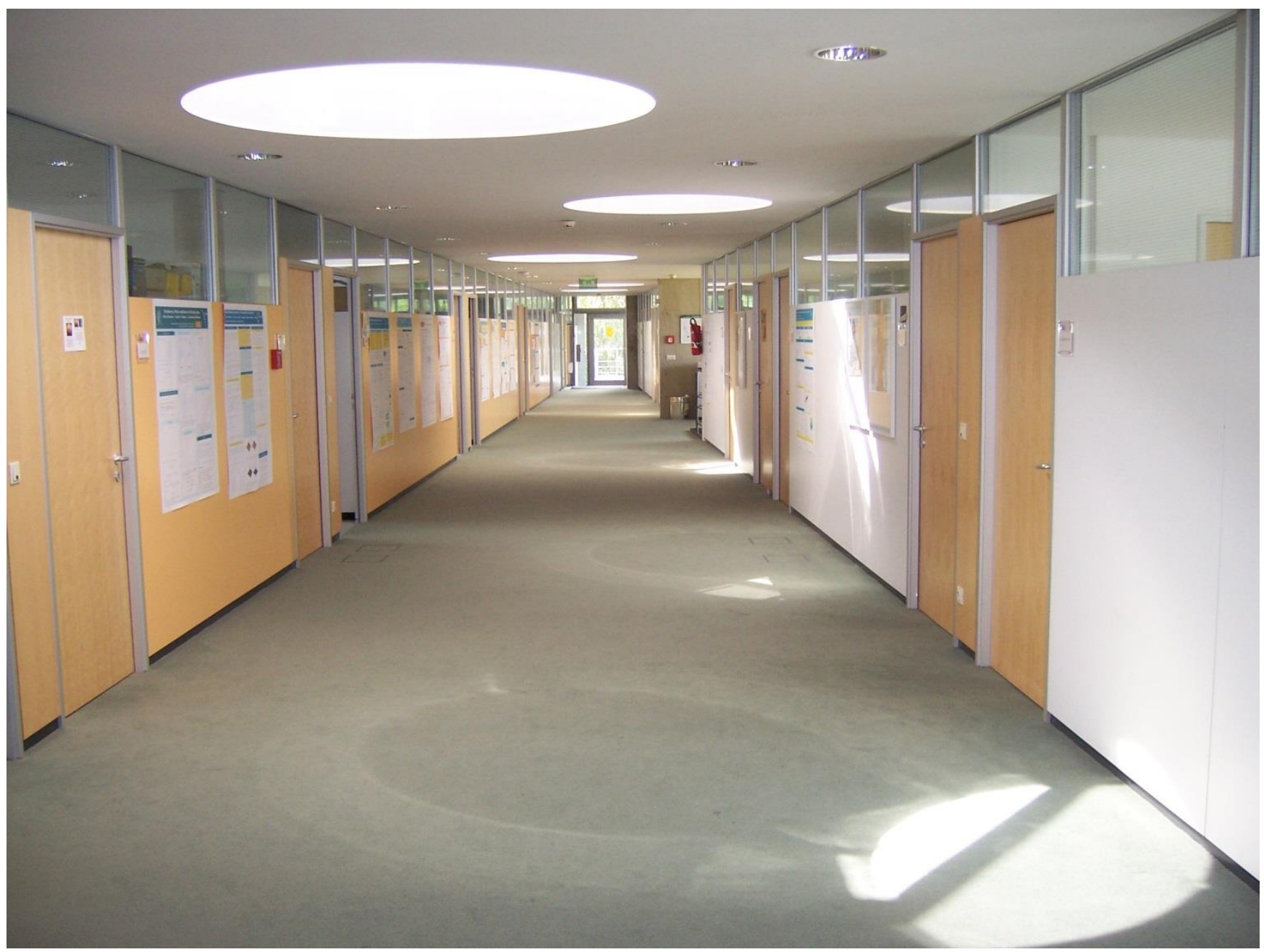

Fig. 7.4 The corridor of the research institute's wing 2B (From Sailer 2010, p. 83. Copyright 2010 by K. Sailer)

\section{Collaboration Patterns and Spatial Integration-The Generic Function of Space}

Patterns of collaboration between staff members in knowledge-intensive workplace environments arguably depend on a variety of work-related factors, such as task structures, working processes, and organizational cultures. Using empirical studies I conducted on benchmark organizations, however, I will show that collaboration is also informed by the spatial configuration of an office. A 3-point scale was used to identify emergent patterns of collaboration, with staff members being asked which of their colleagues they found useful to getting their own work done. I interpret the resulting level of usefulness in relationships among staff members as evidence of emergent collaboration patterns within organizations (as opposed to formal collaboration patterns, which may be thought of as stemming rather from hierarchies, reporting lines, and group affiliation). In the benchmark, the intensity of emergent collaboration ranged from 1.55 (for a medium-sized university department with 69 staff members) to 2.72 (for a small corporate events organizer with 10 staff). The research institute in my study scored 1.79, placing in the lower third of the benchmark. Although size certainly figures in the intensity of emergent collaboration (the two smallest organizations in the benchmark showed the greatest mutual usefulness; see the image on the right in Fig. 7.5), the compactness of the office 
spaces seemed to be the more important factor, as the multivariate analysis in Fig. 7.5 shows.

Compactness of office spaces in this case was modeled as the average metric integration of the whole workspace (i.e., the actual distances along lines of movement measured, in accordance with space syntax methodologies (see Sailer, 2007, for example), from any place in the office to all other places. Figure 7.6 shows the underlying line model of metric integration of the research institute.
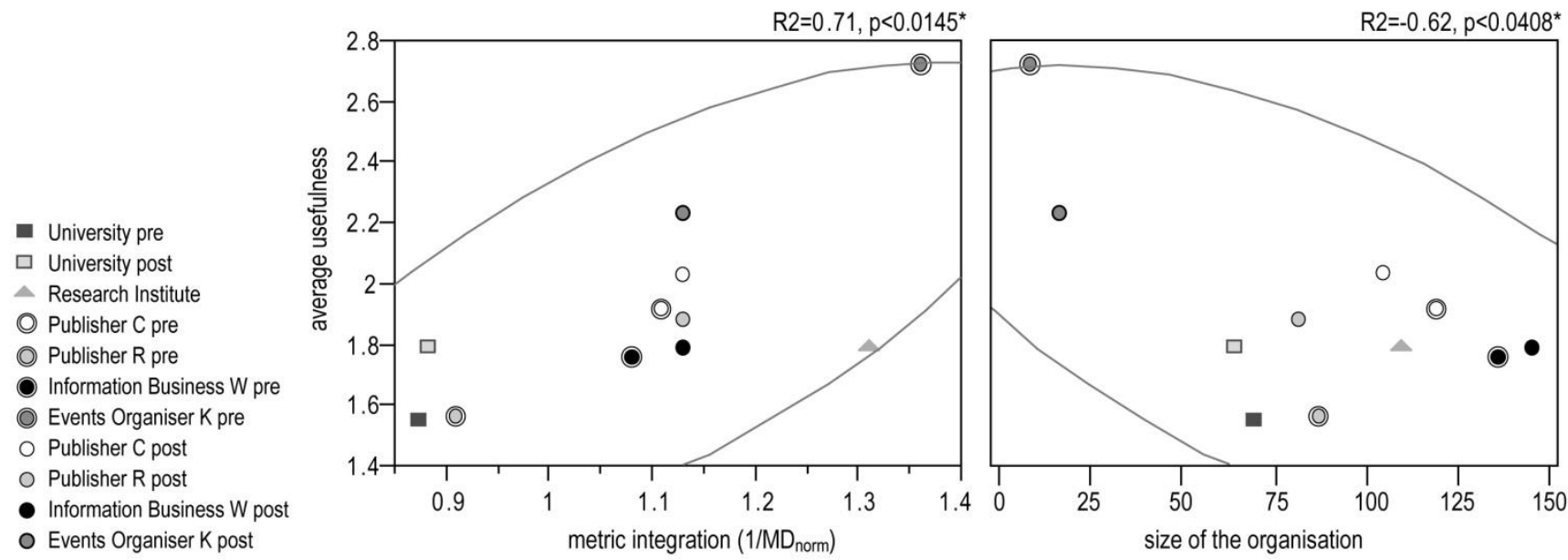

Fig. 7.5 Across a benchmark of 11 organizations, the intensity of emergent patterns of collaboration depends not only on the size of the organizations (left) but also on the compactness and metric integration of their workspaces (right). Metric integration is calculated as mean depth in metric distance from any line to all other lines and averaged across the whole system. In order to compare between systems of different sizes and configurations, metric mean depth is normalized by the office area $(\sqrt{ } \mathrm{sqm})$

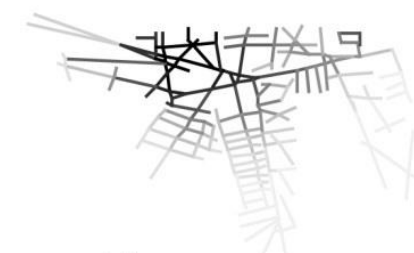

ground floor

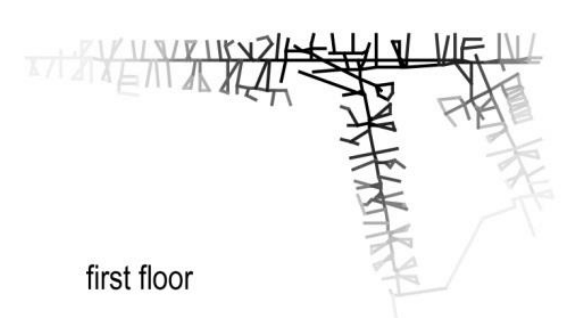

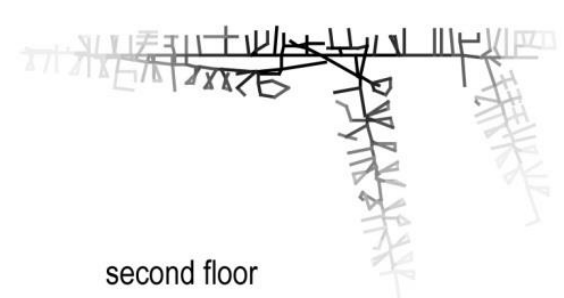

second floor

\footnotetext{
integrated__ segregated
}

Fig. 7.6 Metric integration showing the spatial configuration of the research institute. Darker segments depict more integrated areas; brighter segments depict less integrated areas of the office

Essentially, organizations occupying rather compact office space-those in which walking distances are relatively short and easy-tend toward fairly intense collaborative relationships among staff members. Of course, spatial configuration is not the only factor bearing on collaboration patterns among individuals in workplace environments, a fact that explains the degree of variation shown in the model depicted in Fig. 7.5. This relationship between spatial configuration and emergent organizational behaviors seems to follow a "generic function" of space, as explained by Hillier (1996):

"Generic function refers not to the different activities that people carry out in buildings or the different functional programmes that buildings of different kinds accommodate, but to aspects of human occupancy of buildings that are prior to any of these: that to occupy space means to be aware of the relationships of space to others, that to occupy a building means to move about in it, and to move about in a building depends on being able to retain an intelligible picture of it. Intelligibility and functionality defined as formal properties of spatial complexes 
are the key 'generic functions', and as such the key structures which restrict the field of combinatorial possibility and give rise to the architecturally real." (p. 282)

In this sense a relatively compact office in which the space is easily walkable and in which all areas are within relatively easy reach for everyone allows for heightened awareness and is thus conducive to the formation of relationships among staff members no matter what functional program a building hosts (for further details see Sailer, 2010).

\section{Interaction Patterns and Proximity-Spatial and Transpatial Forms of Solidarity}

In contrast to the previous section's argument that certain functions of space may be of a generic nature, most of the evidence in the literature and in the empirical data underlying this chapter suggests that the effect of spatial configuration is rather ambiguous because similar spatial configurations may lead to distinct organizational responses. This insight is exemplified by the relationship between proximity among actors and their interaction frequency. Figure 7.7 shows characteristic distance curves for the organizations in the benchmark (i.e., the average distance between interaction partners depending on the frequency of their interactions). Quite clearly, daily interactions took place within 15$22 \mathrm{~m}$ (about 50-70 ft) in all organizations (apart from the research institute), yielding a characteristic distance of $18 \mathrm{~m}$ (just under $60 \mathrm{ft}$ ) for daily interaction. By contrast, weekly interaction ranged much further afield: a characteristic distance of $34 \mathrm{~m}$ (about $112 \mathrm{ft}$ ). Although most organizations seem to follow spatially induced interaction routines (overall low distances of daily interaction and significantly longer distances for weekly or monthly contact), the research institute is a prime example for transpatial interaction patterns. Daily interactions in this organization occurred at a distance of more than $42 \mathrm{~m}$ (about $140 \mathrm{ft}$ ) on average, with $22 \%$ of daily interactions spanning more than $80 \mathrm{~m}$ (about $260 \mathrm{ft}$ ). Interactions between people obviously followed rationales other than, or at least in addition to, physical proximity.
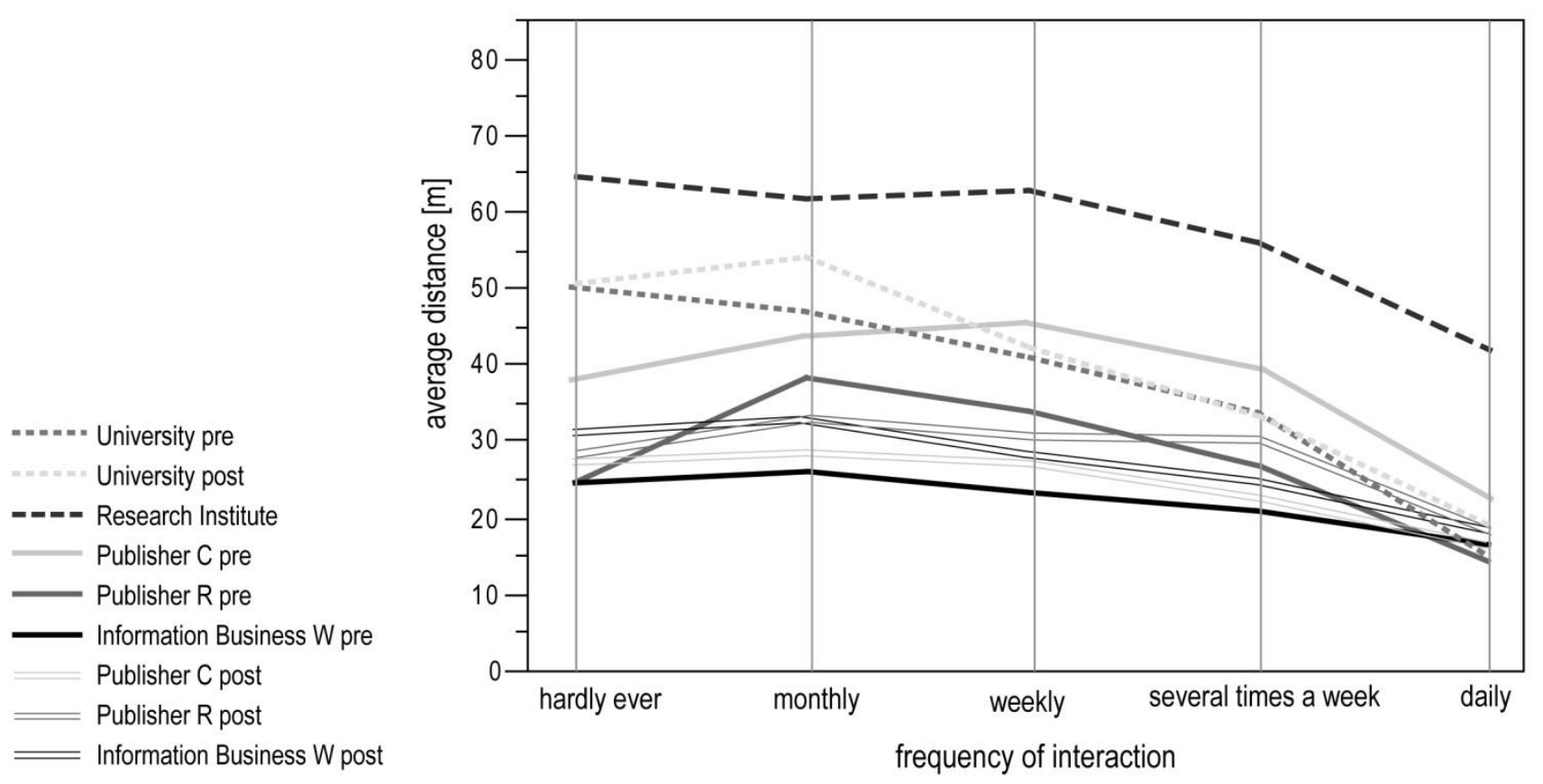

Fig. 7.7 Characteristic distance curves for each organization showing at which distance (on average) different intensities of face-to-face interaction took place; two organizations (events organizer pre and post) were omitted from the benchmark for size reasons; the research institute is shown as black dashed line (From Sailer 2010, p. 239. Copyright 2010 by K. Sailer. Adapted with permission of the author) 
So how did relationships between people form in the research institute if spatial proximity did not seem to be the major driver? I maintain that collaboration between scientists in the research institute were shaped by the open character of the institute as a local place shared between people in their simultaneous co-presence as well as by the global process of specialized knowledge creation in the field of theoretical physics. Staff members at the research institute commented in a variety of ways on the co-presence of others and how it shaped their collaboration:

You need the social contact and the exchange of knowledge to know what other people are doing and what can be learned from them in order to avoid reinventing the wheel. It's a way to accelerate research. Gaining insights is quicker in a group of people or in systems that influence each other than it would be for isolated individuals. (Leader of group DY at the research institute) ${ }^{5}$

Our guest program is something very special because people come and go and you have no chance whatsoever to follow. To have so few people with permanent contracts gives the place a special dynamic. Many people with whom you can discuss your work come here. It so happens that you really do discuss with those around. But imagine if someone else were here; maybe your work would get a very different kick. (Member of group MA at the research institute) $)^{6}$

In other words, the openness of the institute-inviting scientists to work on site on their research ideas -and the resulting levels of co-presence of people who would normally not share the same space did indeed shape collaboration between people. ("You need the social contact." "You really do discuss with those around.") It also introduced a degree of randomness into the patterns of knowing each other, interacting, and collaborating. ("If someone else were here, maybe your work would get a very different kick.") Thus, co-presence as a result of temporary colocation was the first driver of collaborative relationships between individual staff members. Team affiliations and special expertise in a field were additional crucial sources of contact for individual researchers:

In physics you work in very small units, basically your group. (Member of group DY at the research institute)

In our group we are around 50 people at the moment. All of these people are working in a more or less unique area. In some sense this means that the notions or the literature that you use to express your scientific work is common to all of these people. When you just simply say "The Howard model," all of them will understand what the Howard model is. This is not the case if you talk to other physicists... This makes it easy to contact them and to exchange ideas, to [ask] them, "what do you think about my work?" "What do you think about my ideas?" Or "what are you doing?" More precisely, if you consider the whole group that are more than fifty, you can find at least four or five that are very much experts in the same area you are working in... So five people on exactly the topic you are working on. This is great because you can simply share your ideas. You can even share the details of ideas without needing to explain them for several hours and then discuss them. Just when you say something, they will know [what you are talking about] because they are working on the same

\footnotetext{
5 "Man braucht schon den sozialen Kontakt, und den Austausch, was andere Leute machen, was man von wem lernen kann bevor man das Rad neu erfindet, ja, so kann man Wege abkürzen. Der Erkenntnisgewinn geht sicher schneller in der Gruppe oder in der Wechselwirkung der Systeme, als wenn die Leute sich isolieren."

6 "Dieses Gästeprogramm ist schon was Besonderes, dass die Leute hier kommen und gehen, ohne dass man die Chance hat, da mitzukommen. Dass wenig permanente Leute da sind, das verleiht dem Ganzen schon eine besondere Dynamik. Es kommen viele Leute vorbei, mit denen kann man dann diskutieren, und dann diskutiert man halt mit denen und je nachdem wer da wäre, würde die Arbeit vielleicht auch einen ganz anderen Kick bekommen."
} 
thing. This is a very impressive scientific atmosphere. (Member of group EL at the research institute)

As indicated by the four speakers quoted above, work processes seemed to be very specialized ("All of these people are working in a more or less unique area.") and were segregated into areas of expertise that did not involve the organization as a whole. ("In physics you work in very small units." "Gaining insights is quicker in a group of people.") This does not mean that people worked purely for themselves. ("You need the social contact and the exchange of knowledge.") Obviously, working relationships were strongly driven by specialization and the expertise of individuals in a certain field. The high degree of specialization in the research institute ultimately led to increased selectivity in the choice of collaboration partners, as illustrated by the social networks of emergent collaboration patterns (see Fig. 7.8).
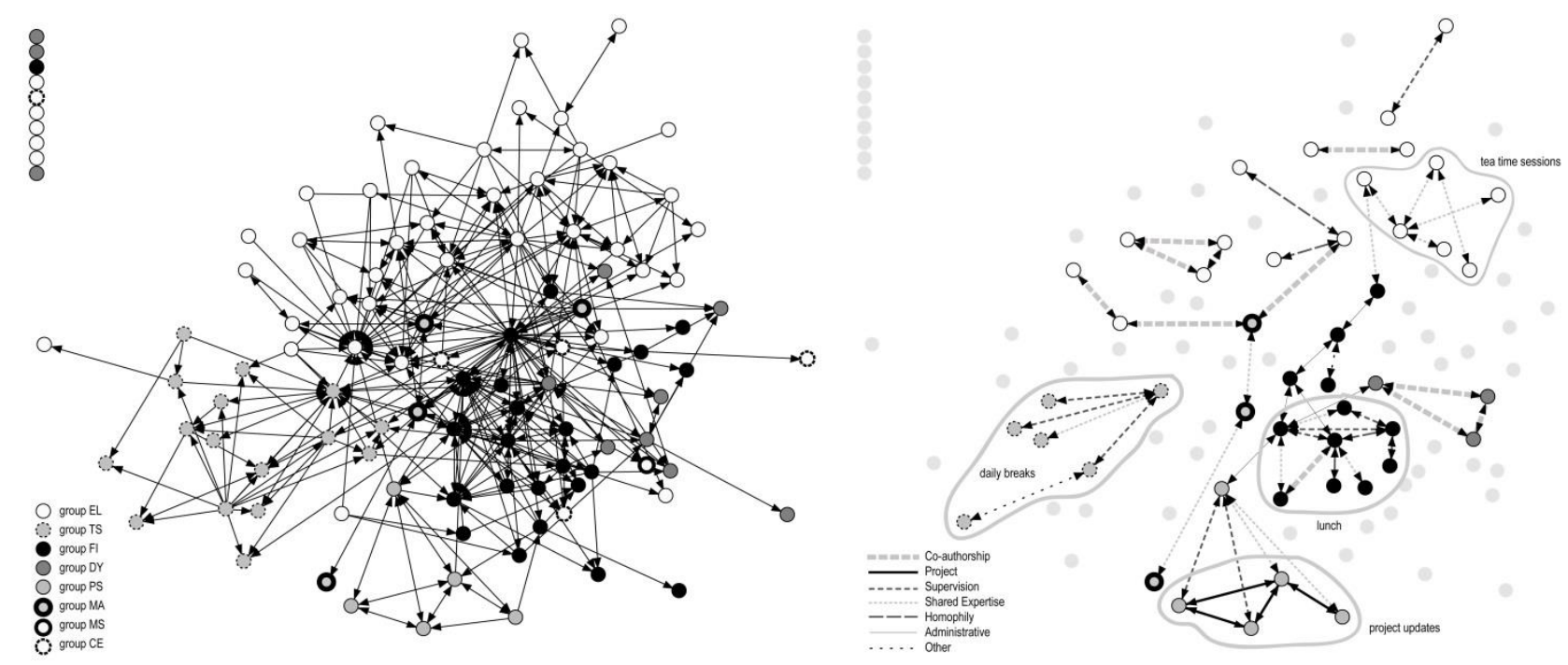

Fig. 7.8 Network of intensive emergent collaboration in the research institute showing all relationships (a) and mutual relationships $(\mathbf{b})$

Although intense relations emerged within and between groups-every person found an average of 5.6 people who were extremely useful (Fig. 7.8a) - the number of ties in the network shrank significantly if one counts only the reciprocal relationships, that is, the pairs of people who found each other very useful (Fig. 7.8b). Only 0.9 reciprocal relationships per person were found (because many of the surveyed people develop no reciprocal ties at all). The network also shows how selectively people chose their collaboration partners. In some groups, such as group EL (shown as white circles), there evolved no coherent, overarching group structure that would have tied everyone in. Instead small clusters appeared, consisting mostly of two or three collaborating scientists. All clusters of more than three

people were involved in specific time-space routines. Examples were group TS, which held daily breaks with the whole group; a cluster within group EL that met for daily sessions at tea time; group PS, which was involved in a joint programming project and met for daily progress reports; and group $\mathrm{FI}$, whose members regularly went for lunch together.

The network diagram in Fig. 7.8b also shows different rationales for relationships and types of collaboration. Although most reciprocal ties were substantiated by collaboration anchored in similar expertise and interests $(27 \%)$, supervisory relations (24\%) and coauthorship $(22 \%)$ were equally important as primary drivers of collaboration. The remaining relationships were administrative in nature $(12 \%)$; centered on projects $(8 \%)$; rooted in ethnic background, language, or some other homophily between actors (4\%); or derived from other underlying rationales $(4 \%)$. In summary, collaboration arose specifically between people who shared knowledge and expertise (supervision, 
collaboration, or coauthorship) or who shared certain tasks and work processes (project work or administration and management). The high degree of specialization in the field of theoretical physics and the particular dynamics at the institute, with its strong visitors program, shaped the patterns of collaboration among individual scientists. These patterns were made possible by co-presence enacted within an openly structured and inviting building and articulated by times-space routines and recurring social behaviors such as daily team meetings, tea breaks, or joint lunches.

The message is that predominantly transpatial forms of solidarity (routines, social events, and expertise) provided the necessary "social glue" for the organization and its emerging collaboration patterns. Spatial forms of solidarity, such as proximity among actors, played only a minor role. Differences between the characteristic distance of daily interaction (42 m, or about $140 \mathrm{ft}$, on average) and weekly interaction (63 m, or about $207 \mathrm{ft}$, on average) were significant, yet distance did not prevent interactions in which scientists were interested:

What I would like is to have the overall walking distances reduced for the group. My group leader sits one floor below me, which is not too bad, but when I am walking over to one of the postdocs with whom I collaborate, it's at the end of wing $A$, which is quite a way... I would like to change the spatial distribution of the groups in order to keep distances within each as short as possible. The distances are really still too long, at least in ours. (Member of group PS, which was spread out over a median distance of $83 \mathrm{~m}$, or just over $270 \mathrm{ft})^{7}$

The disadvantage of the wings are, well, [person S] sits $100 \mathrm{~m}$ [about $330 \mathrm{ft}$ in this direction, or maybe 80 [about $260 \mathrm{ft}$ ], but you just don't walk that far very often. It simply takes too long, and you're liable to get stuck somewhere on the way because you meet other people.

(Leader of group MA, which was spread out over a median distance of $101 \mathrm{~m}$, or about 333 ft. $)^{8}$

Proximity may have facilitated collaboration between researchers in the institute, and distances may have been perceived as a burden, yet a lack of proximity was no major hindrance to collaboration and interactions, for the general co-presence of scientists from all over the world with a shared expertise was appreciated enough that microdistances did not matter that much.

This pattern, an embeddedness of transpatial solidarity within certain spatial configurations, was elaborated by Hillier and Hanson (1984) in their study on the spatiality of societies. They held that relations between individuals could be explained either as a spatial function or as a social function of conceptual closeness, which they call transpatial:

"In their elementary forms, in effect, buildings... can define a relation to others by conceptual analogy, rather than spatial relation. The inhabitant of a house in a village, say, is related to his neighbours spatially, in that he occupies a location in relation to them, but also he relates to them conceptually, in that his interior system of spatialised categories is similar or different from those of his neighbours. He relates, it might be said, transpatially as well as spatially. Now this distinction is very close to that between mechanical and organic solidarity... Durkheim had distinguished between two fundamentally different principles of social solidarity or cohesion: an 'organic' solidarity based on interdependence through differences, such as those resulting from the division of labour; and a 'mechanical' solidarity based on integration through similarities of belief and group structure. This theory was profoundly spatial: organic

\footnotetext{
7 "Was ich schon gerne hätte, ist dass die Gruppe, also dass die Laufwege im Institut ingesamt geringer wären, also mein Chef sitzt noch eine Etage tiefer, das geht noch, aber wenn ich zu den postdocs gehe, mit denen ich zu tun habe, das ist am Ende des A-Flügels und das ist dann schon ein Stück Weg... Ich würde die Gruppen halt raumtechnisch ... verändern, also die Wege innerhalb einer Gruppe möglichst kurz halten, das ist zumindest bei uns in der Gruppe noch zu lang."

8 "Der Nachteil der Flügel ist, der [S], der sitzt 100 m in diese Richtung oder 80, das ist eine Distanz, da geht man nicht einfach so hin. Weil ... es dauert einfach, dann kann man noch irgendwo festhängen, weil man Leute trifft."
} 
solidarity required an integrated and dense space, whereas mechanical solidarity preferred a segregated and dispersed space." (pp. 18-20)

In essence, individuals may relate to each other in a dual way, either by means of spatial closeness (spatiality) or of conceptual closeness (transpatiality). Transpatial affinity, however, does not mean that relationships are nonspatial. Given that homogeneity in values often came with the same preferences for spatial ordering, Hillier and Hanson posited the spatial contextuality of conceptual closeness. My study documents the same spatial contextuality of transpatial solidarity for the research institute, where collaboration was driven by expertise and coauthorship and promoted by specific spatial configurations such as proximity.

\section{Organizational Learning and Its Embeddedness in Physical Space}

The two preceding sections have shown how organizational behaviors such as interaction and collaboration were driven partly by physical space and partly by transpatial solidarity enacted within spatial configurations. Likewise, organizational learning can be embedded in physical space, as illustrated by one of the institute's research groups (PS) and a software development project on which the group collaborated in the spring and summer 2006. The group aimed to replace pieces of software that group members had previously written individually. It turned out that the software all the member had used was very similar but tailored to each one's specific research goals. The first objective of the project was to unify the different software solutions so that there would in future be only one standard software into which each individual could plug in his or her own small specific add-ons. The second objective was to implement parallel computing in order to increase calculation speed and thereby allow the researchers to deal with physics problems that they had not been able to analyze before. This innovation was, hence, intended to improve the understanding of research issues confronting each individual and the group. Group PS contacted one of the IT administrators at the institute for help on a version control system. ${ }^{9}$ This person offered profound support in organizing and setting up the project, leading to the involvement of a computer scientist. After 6 months of joint programming, the group finished the software. Four members continued to use and modify the program, and a new person had started familiarizing himself with it. To calculate something new in the field of group PS, only around one hundred lines of code were needed as a result of the new software. Before the project began, the idea took shape as a common process among the group members:

In our group at least three people were doing more or less the same thing, so we could have used the same program, but in different ways. Only small bits and pieces would have been needed to extend it for use by each of us. It took a relatively long time until we finally decided to combine it all, and now it works a lot better... The idea came from me, or rather, it came continually [smiles], and I eventually initiated the process. (Member of group PS) ${ }^{10}$

How exactly the idea emerged cannot be traced, but the process definitely involved various steps: the insight that group members worked on such similar tasks that efforts could be easily joined ("At least three people were doing more or less the same thing."), recognition of certain barriers that had to be overcome first ("It took a relatively long time."), the awareness of its advantages ("It works a lot better."), and then the group decision ("We finally decided to combine it.").

Group PS followed an approach called extreme programming. Every morning the members met for 15 min to update each other on the progress they had made, to exchange information, to report on

\footnotetext{
${ }^{9}$ Version control systems are commonly used in relatively complex software development projects, specifically for collaborative or joint programming to monitor changes that different people make in the code at different times.

10 "Also in Bezug auf unsere Arbeitsgruppe, es war ja so, dass zumindest drei Leute quasi das gleiche gemacht haben und wir hätten also das gleiche Programm benutzen können, nur auf verschiedene Art und Weise, da wären nur winzige Dinge drumherum zu schreiben gewesen, die uns betreffen. Und es hat relativ lange gedauert, bis wir uns endlich dazu entschieden haben, das mal zusammenzuwerfen und jetzt funktioniert es auch viel besser... Die Idee kam von mir beziehungsweise sie kam kontinuierlich [schmunzelt] und letztendlich habe ich den Anlass gegeben, das so zu tun."
} 
problems, and to adapt objectives if necessary. On a weekly basis, either individuals wrote code for the software or teams of two met to employ methods of pair-programming. ${ }^{11}$ Pair-programming meant that two people sat in front of a computer, with both of them viewing the screen for a defined period of time (e.g., 2 h). While one of them operated the keyboard and typed code, the other person read the code as it was typed, tried to understand what concepts were applied and what specific constructs were used, asked short and specific questions if things were not clear, or commented whenever it seemed possible to use a better solution. This process is said to enhance the quality of code, advance the learning process of the developers, and lend programming a structure that often comes only by doing. If group PS had chosen a more traditional way to program the code, such as assigning members to program defined parts of it individually on their own, then each of their desks, workstations, and offices would have been sufficient to host the collaboration. Instead, the group chose a creative way with the professional assistance of an inhouse expert and thus needed extra spaces where this type of collaborative work could be accommodated. To some degree they were offered by the institute:

For the project meetings we used the end of the corridor of the $A$ wing... The sunny place was very nice for the status updates, which we gave standing in a circle. After the meetings small teams often formed and immediately began with the detailed planning. These people either disappeared into an office or started discussing details in the corridor on the way back to their offices. (IT administrator and organizer of the project) ${ }^{12}$

The physical design of the building offered these bright and sunny multipurpose areas at the end of the A-wings, and the architects had also built in many other spatial opportunities to meet and collaborate, so the members of group PS actually had a choice of spaces to use. Additionally, the organization was open enough to allow its staff members to use facilities as they wished and needed. For example, group PS utilized the open workstations in wing 1D and the group offices in wing 2D (see Figs. 7.9 and 7.10) for joint programming, although both areas had been equipped for use by short-term visitors attending conferences at the institute and were therefore not exactly suitable for accommodating joint programming sessions.
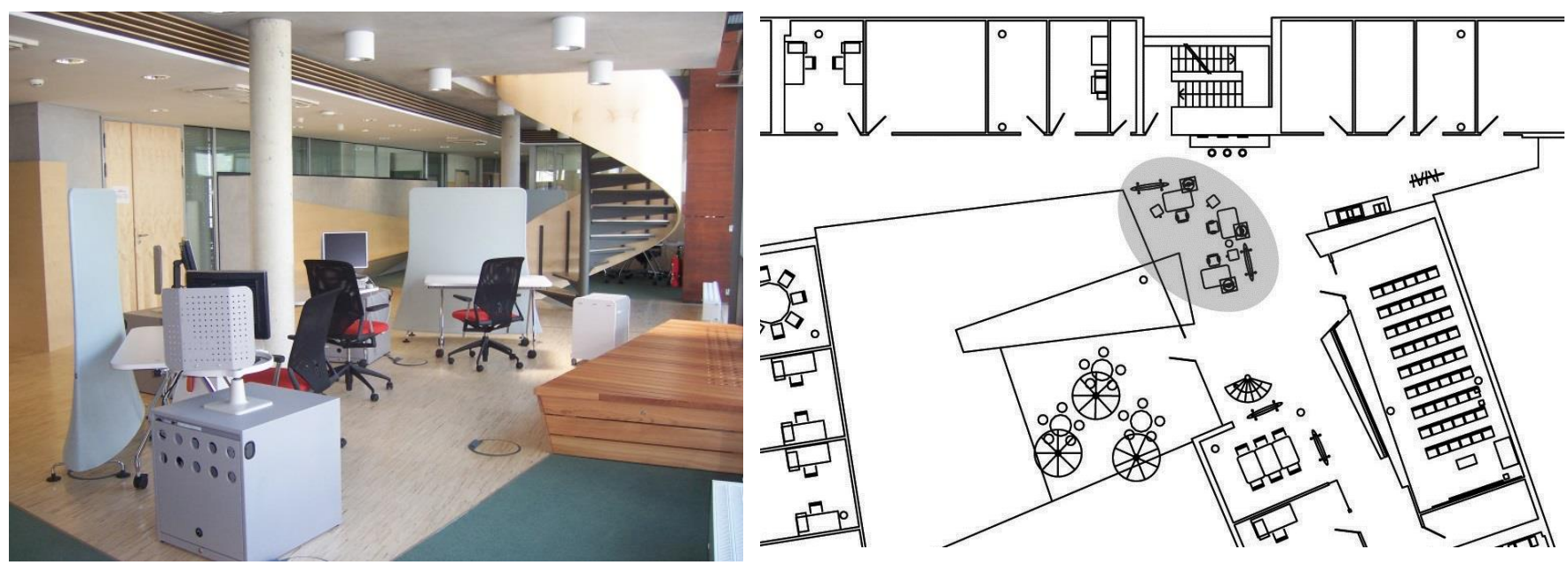

Fig. 7.9 Image (a) and floor plans (b) of the open areas in wing 1D (Copyright 2010 by K. Sailer)

\footnotetext{
${ }^{11}$ For an introduction to extreme programming and pair-programming, see http://en.wikipedia.org/wiki/Extreme programming and http://en.wikipedia.org/wiki/Pair programming (both documents retrieved in 2008).

12 "Für die Projektreffen haben wir das Ende des A-Flügels ... genutzt. Der sonnige Platz war sehr schön für die Statustreffen, die im Stehen abgehalten werden. Nach den Treffen fanden sich oft kleine Teams, die sofort mit der Detailplanung begannen. Die sind dann im Büro veschwunden oder haben einige Details auf den Rückweg im Gang geklärt."
} 


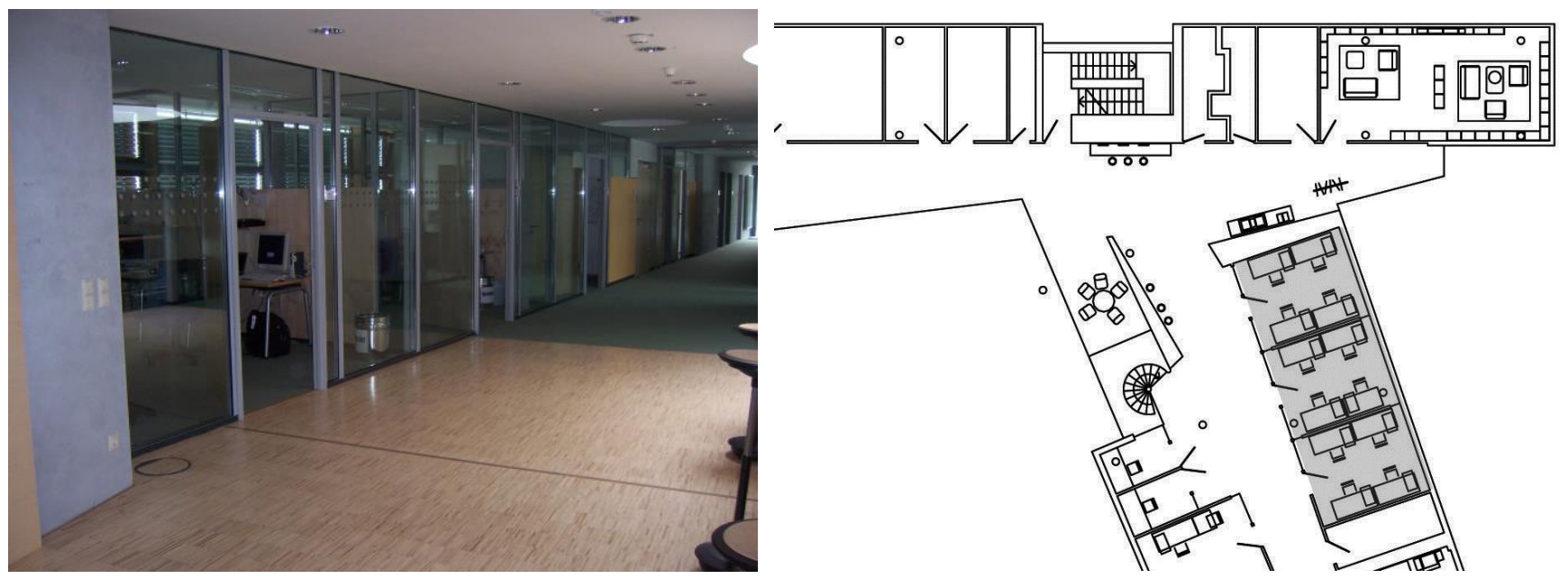

Fig. 7.10 Image (a) and floor plans (b) of the transparent group offices in wing 2D, which were used by group PS for their joint programming sessions (Copyright 2010 by K. Sailer)

The temporary offices in wing 2D were not bookable, the furniture arrangement of open work stations in wing 1D did not allow intense joint computer work, and ordinary collaboration spaces such as seminar rooms or breakout areas lacked computers (laptops were not available). Nonetheless, the project team was able to appropriate institute spaces for their purposes.

But how did organizational learning happen in this case? Who was mainly driving it - the individual, the group, or the whole organization? And what role did space have in the process? The learning effects for the organization were twofold. First, it learned how to save time and be more efficient through collaboration (potentially across group boundaries, too, by involving an in-house IT expert). Second, the organization enhanced and improved its ability to understand a research field and thereby become more intelligent. The way in which the processes were shaped was innovative and creative and therefore resulted in a better product (good quality code that is easily pluggable and extendable). Moreover, the scope and result of the project included the ability to perform parallel computing, opening up potential new fields for doing physics.

The drivers of the learning effort were found at different levels. Individuals had an important part in kicking things off ("I eventually initiated the process"), but at the same time a good deal of motivation came from the group ("the idea came continually") and the supraindividual need for a better program. Individuals such as the IT administrator had a large hand in shaping the way the collaboration patterns evolved and thereby drove the process, but without a dedicated and committed group the project would not have come to an end. However, the group, because of its slight inertia, also seemed to be the main obstacle to learning ("It took a relatively long time until we decided to combine it all"). The group can thus be seen as both the main driver of learning, especially within a loosely structured organization allowing for broad autonomy, and the element that thwarts change and development. In addition, one can reason that the organization as a whole contributed to making such projects possible in the first place by granting a great deal of autonomy to the groups, supporting the groups and individuals, employing IT staff, affording a variety of physical spaces, and allowing for unconventional usage and appropriation of the spaces. This engagement and supply of resources by the organization was highly appreciated by staff members:

I think here there is an idea that the environment should be nice, and everything should be done for helping us to work better. I think that here the institution thinks that we are not only brains connected to a computer. If we are expected to produce something that could be some discoveries, this should be combined into an environment that is nice... I think here it is great attention for this. You can see this in the reading room, they put some games, Asterix comics, the coffee machines, all these small things that are not so small. (Member of group MA) 
I like a lot that we only have to do research e have a lot of freedom e have a lot of support from all levels, from your boss, the institute itself helps you a lot in many things and this you won't find in a university and his makes a great difference. (Member of group DY)

The founding director of the institute underlined the importance of this commitment:

I think the success of our organization lies mainly in the creation of the right climate, where new ideas and developments have the best chance to prosper. I believe new things arise from the creation of an atmosphere. Of course, this is coupled with patterns of behavior. An important issue is generosity, which is crucial, and the delegation of responsibility as early as possible. You have to leave as much latitude as possible for the initiatives of individuals. (Leader of group $E L)^{13}$

In this sense the organization drove the learning efforts and supported individuals or groups in their learning. The contributions of actors at different levels in the research institute I studied underline Nonaka and Takeuchi's (1995) assertion that the core of the learning process lies in the group but that the organization as a whole needs to provide enabling conditions. The evidence from the study discussed in this chapter thus shows that learning was prevalent at all three levels in the observed research institute: the individual, the group, and the organization as a whole.

As outlined above, the learning processes were embedded within physical space. The spaces at the institute gave them enough room to unfold and not only made for a rich variety of meeting opportunities and additional temporary working areas but also created an open atmosphere by means of wide corridors, bright and sunlit spaces, and high visibility within the institute. Conceptually, too, space may have affected organizational learning in two ways. First, co-presence arguably increased the likelihood that people would continue pursuing an innovative project. If a new situation ever called for a collaborative programming project, the previously involved IT administration, who was still on hand, could help apply the lessons learned and could induce a new cycle of organizational learning. Moreover, it was possible that the jointly produced software would lead to new processes of learning and benefit other researchers in the future. Second, the spatial configuration of the institute was likely to continue to shape patterns of interaction and collaboration by forging groups of individuals previously unknown to each other.

Many more discussions arise now because of the new coffee machines. You simply bump into each other there. (Leader of group MA at the research institute) ${ }^{14}$

I love the spaciousness. Every morning when I enter the building, I think "wow." The staircase, the big windows, everything is very bright. It makes you communicate with the people in the wide spaces. You linger on your way somewhere. You see someone coming who you wanted to talk to anyway, and then you stop and start talking. (Member of the research institute's central administration) ${ }^{15}$

Thus, the configuration of physical space in the research institute may pave the way to new opportunities for communication, sharing of knowledge, learning, and change.

\footnotetext{
13 "Der Erfolg unserer Organisation, den sehe ich hauptsächlich darin, ein Klima zu erzeugen, das richtige Klima zu erzeugen, wo neue Ideen und neue Entwicklungen eine möglichst hohe Chance haben, dass sich neue Dinge entwickeln, über die Erzeugung eines Klimas. Das ist natürlich gekoppelt mit Verhaltensmustern. Ein wichtiger Punkt ist Großzügigkeit. Das ist sehr wichtig. Und möglichst frühzeitige Delegation von Verantwortung, da wo es möglich ist. Man muss den Initiativen der Einzelnen möglichst viel Spielraum lassen."

14 "Durch die neuen Kaffeemaschinen, da kommen sehr viel mehr Diskussionen zusammen, weil man sich da einfach trifft."

15 "Ich mag die Großzügigkeit, ich komm hier jeden Morgen in das Haus rein und sage: toll. Die Treppe, die großen Fenster, es ist alles sehr hell. Irgendwie bringt es einen dazu, dass man mit Leuten kommuniziert in den weiten Flächen, dass man auch mal stehen bleibt, sich anlehnt, und sagt, oh, jetzt kommt jemand, den wolltest du mal was fragen oder mit dem hattest du eh was zu besprechen und dann bleibt man stehen."
} 


\section{Conclusions-Who Is Afraid of Physical Space?}

I have contended that the relationship between physical space and organizational behavior is governed by different rationales. On the one hand, spatial configuration may exert a generic function on basic anthropological constituents such as occupancy, movement, and awareness. On the other hand, people regard the relationship between space and organization as being shaped by the interplay between forms of spatial and transpatial solidarity (for a more detailed discussion of both principles, see Sailer \& Penn, 2009, and Sailer \& Penn, 2010). Patterns of transpatial solidarity may differ from one organization to the next. In the research institute I studied, the main identified drivers of emergent interactions and collaboration were the disciplinary character of theoretical physics, the special expertise required by that field, and the nature of the institute as a temporary and shared place creating co-presence among scientists from all over the world. These patterns were enacted within the particular spatial configurations of the institute-its relative compactness as a building, which allowed easy access to all areas within it; its wide corridors; and its plentiful, flexible, and available informal meeting spaces. This setup was underlined again by the story of the programming project conducted by group PS and how that interaction created a potential for organizational learning embedded in space.

From the perspective of research on human geography, stressing the important role of physical space and specifically acknowledging a generic function of space underplays the fundamental principles of human agency; falls short of understanding the interplay between society, action, and space; and instead follows a path of environmental or geodeterminism. Human geographers have criticized that space has been wrongly reduced to a confined container enclosing physical objects. Instead, they posit "subjective agency as the only source of action and hence of change" (Werlen, 1993, p. 3). As a consequence, space has increasingly come to be considered a result of social relations and the relational ordering of social goods and people (Meusburger, 1999, 2008; Weichhart, 1999; Zierhofer, 1999).

For three main reasons the approach presented in this chapter is anything but geodeterministic. First, it keys on physical space as a driver of organizational behaviors. In this chapter I have not examined space as a fixed container but rather have analyzed an elaborate conceptualization of spatial configuration. Space syntax as a morphological approach is relational in itself, for it takes the perspective of an entire system of spaces into account in the analysis of their consequences for and the potential of the quality of life prevalent at one of the system's locations. My study of physical space therefore does not reduce space to a simple container function. Second, I have not taken physical space to be the sole determinant of human behavior. Various parameters emerged as important, including organizational character, research cultures, and human agency. Third, and most important, aggregate human behaviors have been borne in mind. Space is seen to influence the probability of certain behaviors but not the individual behaviors themselves. In a study of cities in relation to the quality of life they create, Hillier, Burdett, Peponis, and Penn (1987) have suggested that cities as configurational and spatial structures create a potentiality:

Cities are mechanisms for generating a potential field of probabilistic co-presence and encounter. What happens beyond that is not the direct effect of the city, but an effect of culture. The prevailing culture may, however, itself be an indirect, evolutionary product of the city... The field of probabilistic co-presence and encounter generated by an urban layout has a definite and describable structure, one which varies greatly with the structuring of space; it can be sparse or dense, localised or globalised, predictable from the intelligible structure of space or unpredictable, and mix inhabitants and strangers in different degrees. In other words, the pattern of co-presence has both a describable pattern and a known cause. ( $p$. 248)

The same potentiality and field of probabilistic co-presence and encounter that Hillier et al. (1987) ascribe to cities can likewise be seen in office spaces. For example, the study of characteristic distance curves has shown that intense interactions have a higher probability of taking place if actors 
are located in proximity to each other. Of course, individual pairs of people may choose to interact at any intensity they wish, no matter how far away they are located from each other, but a distance relationship emerges more or less clearly for each organization when one takes the collective interaction patterns into account statistically.

In conclusion, physical space informs organizational behaviors collectively even though the physicality of a workplace environment is only one factor in an intricate tangle of spatial and transpatial forms of solidarity operating within any organization. I have shown how organizational learning may be embedded in a specific spatial configuration, yet much remains to be learned about its constitution and what part physical space may have in its occurrence.

\section{References}

Ackermann, M. (2005). Systemisches Lernen: Individuelle und organizationale Lernprozesse in Kommunikationsarchitekturen [Systemic learning: Individual and organizational learning processes in communication architectures]. Frankfurt am Main, Germany: Peter Lang Verlag.

Allen, T. J., \& Fustfeld, A. R. (1975). Research laboratory architecture and the structuring of communications. R\&D Management, 5, 153-164.

Allen, T. J., \& Gerstberger, P. G. (1973). A field experiment to improve communications in a product engineering department: The non-territorial office. Human Factors, 15, 487-498.

Amin, A., \& Cohendet, P. (2004). Architectures of knowledge: Firms, capabilities, and communities. Oxford, UK: Oxford University Press.

Amin, A., \& Roberts, J. (2008). Knowing in action: Beyond communities of practice. Research Policy, 37, 353-369.

Argote, L. (1999). Organizational learning: Creating, retaining and transferring knowledge. Boston: Kluwer Academic Publishers.

Argyris, C., \& Schön, D. A. (1996). Organizational learning II: Theory, method, and practice. Reading, MA: Addison-Wesley.

Becker, F. (1981). Work space: Creating environments in organizations. New York: Praeger Publishers Inc.

Becker, F., \& Sims, W. (2001, October). Offices that work: Balancing communication, flexibility and cost [Electronic Version]. Ithaca, NY: International Workplace Studies Program, Cornell University. Retrieved from http://iwsp.human.cornell.edu/file uploads/offices1 1238256905.pdf. Also available at: http://media.miamiherald.com/smedia/2008/07/27/10/IWS 0002.source.prod affiliate.56.pdf

Boje, A. (1971). Open plan offices. London: Business Books.

Boyce, P. R. (1974). Users' assessment of a landscaped office. Journal of Architectural Research, 3(3), 44-62.

Brookes, M. J., \& Kaplan, A. (1972). The office environment: Space planning and effective behavior.Human Factors, 14, 373-391.

Burns, T., \& Stalker, G. M. (1961). The management of innovation. London: Tavistock Publications.

CABE (Commission for Architecture and the Built Environment). (2005). The impact of officedesign on business performance. London: The Commission for Architecture and the BuiltEnvironment.

Carey, A. (1967). The Hawthorne studies: A radical criticism. American Sociological Review, 32,403-416.

Chawla, S., \& Renesch, J. (Eds.). (1995). Learning organizations: Developing cultures for tomorrow's workplace. Portland, OR: Productivity Press.

Clearwater, Y. (1980). User's assessment of a landscaped office. Doctoral dissertation, University of California, Davis, CA. 
Cook, S. D. N., \& Yanow, D. (1996). Culture and organizational learning. In M. D. Cohen \&L. S. Sproull (Eds.), Organizational learning (pp. 430-459). Thousand Oaks, CA: Sage.

Cyert, R. M., \& March, J. G. (1963). A behavioral theory of the firm. Englewood Cliffs, NJ: Prentice-Hall.

Dilworth, R. (1995). The DNA of the learning organization. In S. Chawla \& J. Renesch (Eds.), Learning organizations: Developing cultures for tomorrow's workplace (pp. 243-255). Portland, OR: Productivity Press.

Duncan, R., \& Weiss, A. (1979). Organizational learning: Implications for organizational design. In B. M. Staw (Ed.), Research in organizational behavior (Vol. 1, pp. 75-123). Greenwich, CT:

JAI Press.

Faulconbridge, J. R. (2006). Stretching tacit knowledge beyond a local fix? Global spaces of learningin advertising professional service firms. Journal of Economic Geography, 6, 517-540.

Fayard, A.-L., \& Weeks, J. (2007). Photocopiers and water-coolers: The affordances of informal interaction. Organization Studies, 28, 605-634.

Fischer, G. N. (1997). Individuals and environment: A psychosocial approach to workspace. Berlin, Germany/New York: De Gruyter.

Förster, J., Friedman, R. S., Butterbach, E. B., \& Sassenberg, K. (2005). Automatic effects of deviancy cues on creative cognition. European Journal of Social Psychology, 35, 345-359.

Gertler, M. S. (1997). Between the global and the local: The spatial limits to productive capital. In K. Cox (Ed.), Spaces of globalization: Reasserting the power of the local (pp. 45-63). New York: The Guilford Press.

Gertler, M. S. (2003). Tacit knowledge and the economic geography of context, or the undefinable tacitness of being (there). Journal of Economic Geography, 3, 75-99.

Gieryn, T. F. (2002). What buildings do. Theory and Society, 31, 35-74.

Granath, J. A., Lindahl, G. A., \& Adler, N. (1995, June). Organizational learning supported by design of space, technical systems and work organization: A case study from an electronic design department. Paper presented at the 5th international conference of Flexible Automation and Intelligent Manufacturing (FAIM), Stuttgart, Germany.

Hanson, A. (1978). Effects of a move to an open landscape office. Dissertation Abstracts International, 39(6), 3046B.

Hedberg, B. (1981). How organizations learn and unlearn. In P. C. Nystrom \& W. H. Starbuck (Eds.), Handbook on organizational design (Vol. 1, pp. 3-27). Oxford, UK: Oxford University Press.

Heerwagen, J., Kampschroer, K., Powell, K., \& Loftness, V. (2004). Collaborative knowledge work environments. Building Research and Information, 32, 510-528.

Hillier, B. (1996). Space is the machine: A configurational theory of architecture. Cambridge, UK: Cambridge University Press.

Hillier, B., Burdett, R., Peponis, J., \& Penn, A. (1987). Creating life: Or, does architecture determine anything? Architecture et Comportement/Architecture and Behaviour, 3, 233-250. Retrieved from http://discovery.ucl.ac.uk/101/. See also http://eprints.ucl.ac.uk/101/1/hillier-etal-1987-creating-life.pdf

Hillier, B., \& Hanson, J. (1984). The social logic of space. Cambridge, UK: Cambridge University Press.

Huber, G. P. (1991). Organizational learning: The contributing processes and the literatures. Organization Science, 2, 88-115.

Hundert, A. T., \& Greenfield, N. (1969). Physical space and organizational behavior: A study of an office landscape. Proceedings of the 77th Annual Convention of the American Psychological Association, 4, 601-602.

Isaacs, W. (1999). Dialogue and the art of thinking together. New York: Random House.

Ives, R. S., \& Ferdinands, R. (1974). Working in a landscaped office. Personnel Practice Bulletin, 30, 126141. 
Kampschroer, K., \& Heerwagen, J. (2005). The strategic workplace: Development and evaluation. Building Research and Information, 33, 326-337.

Kampschroer, K., Heerwagen, J., \& Powell, K. (2007). Creating and testing workplace strategy. California Management Review, 49(2), 119-137.

Kelter, J. (2006). Office-Excellence-Check: Ergebnisse der Zwischenauswertung zur Orgatec 2006 [Office excellence check: Results of the interim analysis at Orgatec 2006]. Stuttgart, Germany: Fraunhofer Institut Arbeitswirtschaft und Organisation.

Kelter, J. (2007, September). Office Excellence: Konzepte, Messung, Bewertung [Office excellence: Concepts, measurement, evaluation]. Paper presented at the A+A Congress, 30th international congress on Occupational Health and Safety, Düsseldorf, Germany.

Kelter, J., \& Kern, P. (2006, March). Office Excellence-Kennzahlen für Büroqualität [Office excellenceQuality benchmarks for office]. Paper presented at the 52nd Congress of the Gesellschaft für Arbeitswissenschaft, Stuttgart, Germany.

Klein, L. (1999). Lebensfähige Strukturen der lernenden Organization: Beispiel Human Resource Management [Viable structures of the learning organization as exemplified by human resource management]. In M. Schwaninger (Ed.), Intelligente Organizationen: Konzepte für turbulente Zeiten auf der Grundlage von Systemtheorie und Kybernetik, Wissenschaftliche Jahrestagung der Gesellschaft für Wirtschafts- und Sozialkybernetik vom 2.-4. Oktober 1997 in St. Gallen, Schweiz (pp. 177-188). Berlin, Germany: Duncker \& Humblot.

Kristensen, T. (2004). The physical context of creativity. Creativity and Innovation Management, 13, 89-96.

Levinthal, D. A. (1991). Organizational adaptation and environmental selection-interrelated processes of change. Organization Science, 2, 140-145.

Levinthal, D. A., \& March, J. G. (1993). The myopia of learning. Strategic Management Journal, 14, 95112.

Levitt, B., \& March, J. G. (1996). Organizational learning. In M. D. Cohen \& L. S. Sproull (Eds.), Organizational learning (pp. 516-540). Thousand Oaks, CA: Sage.

Lewis, M., \& Moultrie, J. (2005). The organizational innovation laboratory. Creativity and Innovation Management, 14, 73-83.

Lipshitz, R., Popper, M., \& Friedman, V. J. (2002). A multifacet model of organizational learning. The Journal of Applied Behavioral Science, 38, 78-98.

Malmberg, A., \& Maskell, P. (2002). The elusive concept of localization economies: Towards a knowledgebased theory of spatial clustering. Environment and Planning A, 34, 429-449.

March, J. G. (1991). Exploration and exploitation in organizational learning. Organization Science, 2, 7187.

March, J. G., \& Olsen, J. P. (1976). Ambiguity and choice in organizations. Bergen, Norway: Universitetsforlaget.

March, J. G., Sproull, L. S., \& Tamuz, M. (1991). Learning from samples of one or fewer. Organization Science, 2, 1-13.

Maskell, P., \& Malmberg, A. (1999). Localised learning and industrial competitiveness. Cambridge Journal of Economics, 23, 167-185.

Massey, D. (1999). Power-geometries and the politics of space-time: Vol. 2. Hettner-Lecture. Heidelberg, Germany: Department of Geography, Heidelberg University.

Meusburger, P. (1999). Subjekt-Organisation-Region: Fragen an die subjektzentrierte Handlungstheorie [Subject-organization-region: Questions for subject-centered action theory]. In P. Meusburger (Ed.), Handlungszentrierte Sozialgeographie: Benno Werlens Entwurf in kritischer Diskussion: Vol. 130. Erdkundliches Wissen (pp. 95-132). Stuttgart, Germany: Franz Steiner. 
Meusburger, P. (2008). The nexus of knowledge and space. In P. Meusburger, M. Welker, \& E. Wunder (Eds.), Clashes of knowledge: Orthodoxies and heterodoxies in science and religion: Vol. 1. Knowledge and space (pp. 35-90). Dordrecht, the Netherlands: Springer.

Meusburger, P. (2009). Milieus of creativity: The role of places, environments, and spatial contexts. In P. Meusburger, J. Funke, \& E. Wunder (Eds.), Milieus of creativity: An interdisciplinary approach to spatiality of creativity: Vol. 2. Knowledge and space (pp. 97-153). Dordrecht, the Netherlands: Springer.

Muschiol, R. (2006, March). Begegnungsqualität in Bürogebäuden [The quality of encounters in office buildings]. Paper presented at the 52nd Kongress der Gesellschaft für Arbeitswissenschaft, Stuttgart, Germany.

Nonaka, I., \& Takeuchi, H. (1995). The knowledge-creating company: How Japanese companies create the dynamics of innovation. New York/Oxford, UK: Oxford University Press.

Oldham, G. R., \& Brass, D. J. (1979). Employee reactions to an open-plan office: A naturally occurring quasi-experiment. Administrative Science Quarterly, 24, 267-284.

Penn, A., Desyllas, J., \& Vaughan, L. (1999). The space of innovation: Interaction and communication in the work environment. Environment and Planning B: Planning and Design, 26, 193-218.

Peponis, J., Bafna, S., Bajaj, R., Bromberg, J., Congdon, C., Rashid, M., et al. (2007). Designing space to support knowledge work. Environment and Behavior, 39, 815-840.

Peters, T. (1992). Liberation management: Necessary disorganization for the nanosecond nineties. London: Macmillan.

Pfeffer, J. (1982). Organizations and organization theory. Cambridge, MA: Ballinger.

Prange, C. (1999). Organizational learning: Desperately seeking theory? In M. Easterby-Smith, L. Araujo, \& J. G. Burgoyne (Eds.), Organizational learning and the learning organization: Developments in theory and practice (pp. 23-43). London: Sage.

Price, I. (2007). Lean assets: New language for new workplaces. California Management Review, 49(2), $102-118$.

Probst, G. J. B., \& Büchel, B. (1998). Organisationales Lernen. Wettbewerbsvorteil der Zukunft [Organizational learning: The competitive advantage of the future] (2nd ed.). Wiesbaden, Germany: Gabler.

Sailer, K. (2007). Movement in workplace environments: Configurational or programmed? In A. S. Kubat, Ö. Ertekin, Y. I. Güney, \& E. Eyüboglu (Eds.), Proceedings of the sixth international space syntax symposium: Vol. 2 (pp. 068-01-068-14). Istanbul, Turkey: ITU Faculty of Architecture.

Sailer, K. (2010). The space-organisation relationship: On the shape of the relationship between spatial configuration and collective organisational behaviours. Doctoral dissertation, Technical University Dresden, Dresden. Retrieved from http://www.qucosa.de/fileadmin/data/qucosa/documents/3842/Sailer PhD final print.pdf

Sailer, K., Budgen, A., Lonsdale, N., Turner, A., \& Penn, A. (2008, July). Evidence-based design: Theoretical and practical reflections of an emerging approach in office architecture. Paper presented at the Design Research Society Conference, Sheffield, UK.

Sailer, K., Budgen, A., Lonsdale, N., Turner, A., \& Penn, A. (2009, June). Comparative studies of offices pre and post: How changing spatial configurations affect organisational behaviours. Paper presented at the 7th international space syntax symposium, Stockholm.

Sailer, K., \& Penn, A. (2007, May). The performance of space: Exploring social and spatial phenomena of interaction patterns in an organization. Paper presented at the International Architecture + Phenomenology Conference, Haifa, Israel.

Sailer, K., \& Penn, A. (2009, June). Spatiality and transpatiality in workplace environments. Paper presented at the 7th international space syntax symposium, Stockholm. 
Sailer, K., \& Penn, A. (2010, May). Towards an architectural theory of space and organisations: Cognitive, affective and conative relations in workplaces. Paper presented at the 2nd workshop on Architecture and Social Architecture, EIASM, Brussels, Belgium.

Sitkin, S. B. (1996). Learning through failure: The strategy of small losses. In M. D. Cohen \& L. S. Sproull (Eds.), Organizational learning (pp. 541-577). Thousand Oaks, CA: Sage.

Soja, E. W. (1996). Thirdspace: Journeys to Los Angeles and other real-and-imagined places. Malden, MA/Oxford, UK: Blackwell Publishing.

Starbuck, W. H. (1992). Learning by knowledge-intensive firms. Journal of Management Studies, 29, 713740.

Steele, F. I. (1973). Physical settings and organization development. Reading, MA: Addison-Wesley.

Sundstrom, E. (1986). Work places: The psychology of the physical environment in offices and factories. Cambridge, UK: Cambridge University Press.

Sundstrom, E., Herbert, R. K., \& Brown, D. W. (1982). Privacy and communication in an open plan office: A case study. Environment and Behavior, 14, 379-392.

Sutton, R. I., \& Rafaeli, A. (1987). Characteristics of work stations as potential occupational stressors. The Academy of Management Journal, 30, 260-276.

Toker, U., \& Gray, D. O. (2008). Innovation spaces: Workspace planning and innovation in U.S. university research centers. Research Policy, 37, 309-329.

Tomlin, B., \& Allen, T. J. (1977, June). Organizational structure and inter-location communication in an R\&D organization (Working Paper No. 940-77). Cambridge, MA: Alfred P. Sloan School of Management, MIT. Retrieved from http://dspace.mit.edu/bitstream/handle/1721.1/1930/SWP-094003581816.pdf?sequence $=1$

von Hippel, E. (1988). The sources of innovation. Oxford, UK/New York: Oxford University Press.Wasserman, S., \& Faust, K. (1994). Social network analysis: Methods and applications. Cambridge, UK: Cambridge University Press.

Weichhart, P. (1999). Die Räume zwischen den Welten und die Welt der Räume. Zur Konzeption eines Schlüsselbegriffs der Geographie [The spaces between the worlds and the world of spaces: On the inception of a key concept of geography]. In P. Meusburger (Ed.), Handlungszentrierte Sozialgeographie: Benno Werlens Entwurf in kritischer Diskussion: Vol. 130. Erdkundliches Wissen (pp. 67-94). Stuttgart, Germany: Franz Steiner.

Weick, K. E. (1995). Sensemaking in organizations. Thousands Oaks, CA: Sage.

Weick, K. E., \& Roberts, K. H. (1993). Collective mind in organizations: Heedful interrelating on flight decks. Administrative Science Quarterly, 38, 357-381.

Werlen, B. (1993). Society, action and space: An alternative human geography (G. Walls, Trans.). London: Routledge.

Werth, L., \& Förster, J. (2002). Wie Sie als Führungskraft Kreativität steigern oder blockieren können [How you as an executive can increase or block creativity]. Wirtschaftspsychologie, 2, 13-20.

Wineman, J., Kabo, F., \& Davis, G. F. (2009). Spatial and social networks in organizational innovation. Environment and Behavior, 41, 427-442.

Zierhofer, W. (1999). Die fatale Verwechslung: Zum Selbstverständnis der Geographie [The disastrousmistake: On the self-conception of geography]. In P. Meusburger (Ed.), Handlungszentrierte Sozialgeographie: Benno Werlens Entwurf in kritischer Diskussion: Vol. 130. Erdkundliches Wissen (pp. 163-186). Stuttgart, Germany: Franz Steiner. 